\title{
Drought variability and trend over the Lombardy plain from meteorological station records
}

\author{
Gandolfi $^{1,}$, C., Facchi ${ }^{1}$, A., Crespi ${ }^{1}$, A., Rienzner ${ }^{1}$, M., and Maugeri ${ }^{2}$, M. \\ ${ }^{1}$ Department of Agricultural and Environmental Sciences, Università degli Studi di Milano, \\ via Celoria 2, 20133 Milan (Italy) \\ claudio.gandolfi@unimi.it \\ 2 Department of Environmental Science and Policy, Università degli Studi di Milano, \\ via Celoria 2, 20133 Milan (Italy)
}

\begin{abstract}
The spatial and temporal variability of droughts over the period 1951-2017 for a portion of Lombardy plain (Northern Italy) was reconstructed starting from a quality-checked and homogenized database of long precipitation and temperature station records covering the study region. The monthly meteorological series were interpolated over the period 1951-2017 onto a 30 -arc second resolution grid covering the area by means of an anomaly-based procedure and the gridded fields were used to extract for each cell the series of two standardized drought indices: Standardized Precipitation Index (SPI) and Standardized Precipitation-Evapotranspiration Index (SPEI). SPI and SPEI trend analyses were performed on annual and seasonal scales at both regional and grid-point levels. Theil-Sen test on SPI values highlighted a significant drying tendency (Mann-Kendall p-value $<0.05)$ for summer only $\left(-0.14\right.$ decade $\left.^{-1}\right)$, while SPEI series exhibited a more negative summer trend $\left(-0.22\right.$ decade $\left.^{-1}\right)$ and significant reductions also in spring and annual values ( -0.14 and -0.17 decade $^{-1}$, respectively), suggesting an increase of evapotranspiration rates driven by higher temperature. Moreover, the trend analyses at grid cell level highlighted a greater negative and significant tendency for the western and southern part of the domain. Similar outcomes were obtained by assessing the temporal evolution of drought features over the decades in terms of frequency, duration and severity.
\end{abstract}

Keywords: drought, SPI, SPEI, trend analysis, observations

\section{Introduction}

Variations in hydrological regime are expected in the future at global scale driven by increasing temperature. Extreme events, in term of both intense precipitation and droughts, could become more frequent and severe with relevant negative impacts on ecosystems and on several human activities, such as agriculture (IPCC, 2014; 2018). However, the distribution of climate change and impacts could be highly variable in space: in Europe for example wetting tendencies in the North and drier regimes in Mediterranean areas were depicted, especially for summer and spring (Spinoni et al., 2018). The temporal variability in hydrological regime is generally analyzed by means of standardized drought indicators, the most common ones are computed from meteo- 
rological records, such as precipitation and water deficits due to evapotranspiration (Tsakiris et al., 2007; Vincente-Serrano et al., 2014). In Italy, a general increase in drought events was pointed out for Central and Southern regions over recent decades by several studies, even though the observed trends are strongly influenced by the analyzed period and the surface heterogeneity (Buttafuoco et al., 2015; Vergni and Todisco, 2011; Piccarreta et al., 2004). Drought characterization over Northern Italy, especially for the Po Plain and Pre-Alps, is less systematically discussed in scientific literature. However, an increasing drought occurrence was observed for the area, especially during the most recent decades (Stagge et al., 2017; Brunetti et al., 2009). Improving the available information about the variability of water resources for Northern Italian plain could support future local water managements and adaptation strategies, especially for agricultural production, which highly relies on irrigation and, therefore, on water availability.

In this framework, the spatio-temporal trend and variability of droughts were investigated over a portion of Po Plain in Lombardy $\left(9^{\circ} 12^{\prime}-10^{\circ} 30^{\prime} \mathrm{E}\right.$ and $\left.45^{\circ} 00^{\prime}-45^{\circ} 45^{\prime} \mathrm{N}\right)$ for the period 1951-2017. The monthly series of Standardized Precipitation Index (SPI) and of Standardized Precipitation-Evapotranspiration Index (SPEI) were reconstructed by using a dense database of checked and homogenized precipitation and temperature records covering the area. The weather station records were interpolated onto a 30-arc second resolution grid in order to assess the spatial variability of drought at local scale and to compute SPI and SPEI mean regional series. Trends in SPI and SPEI seasonal and annual records as well as in main drought features were evaluated at both regional and grid point scales over both the whole 1951-2017 interval and on shorter time windows.

\section{Data and Methods}

The study area is located in the middle of Northern Italy and covers about $8500 \mathrm{~km}^{2}$ encompassing the central part of southern Lombardy and, to a lesser extent, the northern Emilia-Romagna $\left(9^{\circ} 12^{\prime}-10^{\circ} 30^{\prime} \mathrm{E}\right.$ and $45^{\circ} 00^{\prime}-45^{\circ} 45^{\prime} \mathrm{N}$, Fig. 1). In particular, the domain includes the lower part of Adda river basin and it is largely characterized by a flat and homogeneous surface, with pre-Alpine reliefs occurring in the northernmost part only. In the area, intensive agriculture, mainly based on maize and pasture, is managed by using an extensive irrigation network supplied by water from main rivers. 42 monthly precipitation series and 13 monthly maximum and minimum temperature series were retrieved for the domain, or very close to it, spanning the period 19512017. In addition, in order to better represent the borders, the further available series for stations located within a larger box centered on the study area were included, reaching more than 100 sites for precipitation and 20 sites for temperature.

The series were retrieved from the regional services (ARPA Lombardia, ARPA EmiliaRomagna, ARPA Veneto, ARPA Piemonte), the archives of the former Italian Hydrographic Service and previous projects focusing on historical data collection and homogenization. Temperature series were checked for quality and homogeneity by 
means of the Craddock test (Craddock, 1968) and homogenization was applied on 8 maximum and minimum temperature series, while precipitation records were not checked since they were derived from the database already analyzed by Crespi et al. (2018a) for assessing the hydrological cycle over the upper Adda basin.

The 1951-2017 monthly precipitation and mean temperature, as average of maximum and minimum values, records were interpolated onto a 30 -arc second resolution Digital Elevation Model (DEM) covering the domain by means of the anomaly method (see, e.g., New et al., 2000; Isotta et al., 2014; Scapin et al., 2015). The gridded fields are obtained by superimposing a field of long-term means, i.e. 30-year climatologies, and the field of anomalies, i.e. the departures from the normals. The 1961-1990 precipitation and temperature normals were computed for all stations after filling the monthly gaps in the 30-year period and for both variables they were interpolated by applying a local weighted linear regression versus elevation (Daly et al., 2002; Brunetti et al., 2014; Crespi et al., 2018b). In order to improve the data coverage for climatology interpolation, the temperature database was integrated with the 1961-1990 monthly normals of 125 sites located within the outer box and retrieved from the database used in Brunetti et al. 2014.

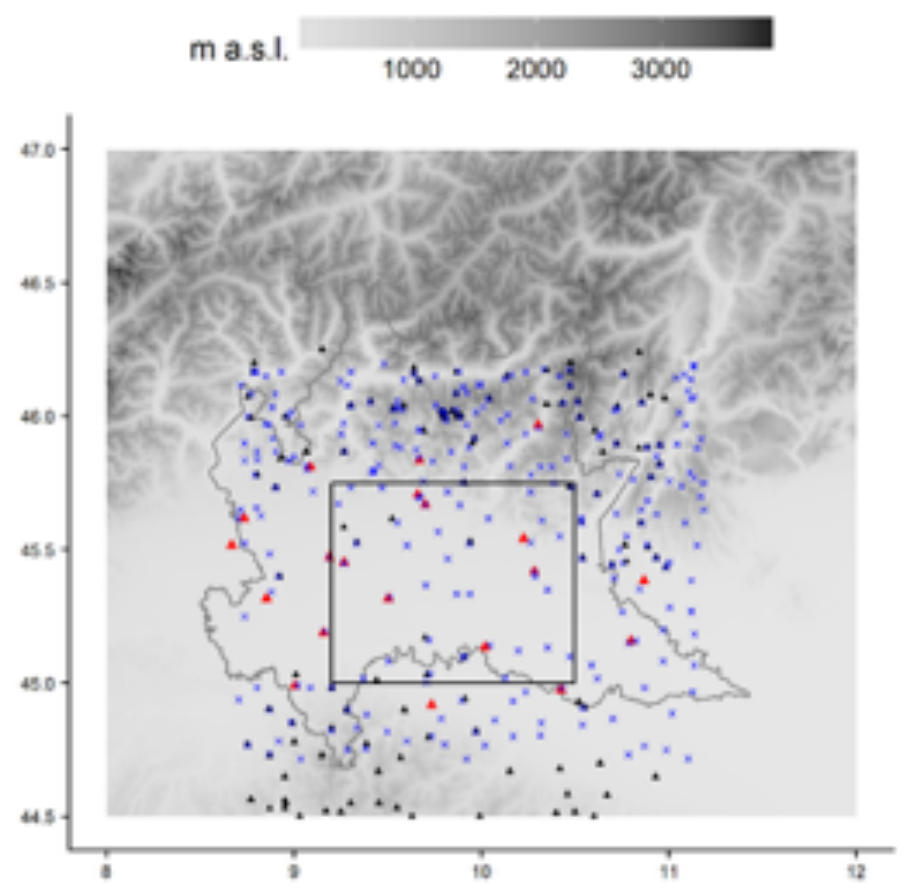

Fig. 1: Study domain (black box) and station distribution: blue crosses are precipitation sites, red triangles are temperature series and the blue triangles report the 1961-1990 monthly temperature normals added for climatology interpolation. 
The station monthly anomalies, i.e. differences for temperature and ratios for precipitation from the normals, were gridded by means of the weighted averaging scheme described in Crespi et al. (2018b).

The 1951-2017 monthly series in absolute values were finally computed by adding (multiplying) the gridded temperature (precipitation) anomalies to (times) the gridded climatologies.

1951-2017 SPI and SPEI series were computed both at cell level from the interpolated fields and at regional level as areal average of all points in the domain.

The deficit series used to derive SPEI were computed as the difference between monthly precipitation and potential evapotranspiration (PET). PET was calculated by Thornthwaite's equation (Thornthwaite, 1948) based on mean temperature only and, therefore, suitable for climatic reconstruction in the past when other meteorological observations, such as wind and relative humidity, are very few.

Trends analyses were assessed by means of Theil-Sen and Mann-Kendall tests, thereafter referred as TS and MK respectively.

\section{Results and discussion}

The 1951-2017 regional SPI and SPEI series were computed by averaging the gridded precipitation and deficit series of all grid cells and on accumulation periods of 3 and 12 months (SPI-3, -12, SPEI-3, -12). Trend evaluation was performed at seasonal scale by considering SPI-3 and SPEI-3 values in February for winter, May for spring, August for summer and November for autumn an on annual scale by extracting SPI-12 and SPEI-12 values in December. TS test on SPI values highlighted a significant drying tendency $(\mathrm{MK}$ p-value $<0.05)$ for summer only $\left(-0.14\right.$ decade $\left.^{-1}\right)$, while SPEI series exhibited a more negative summer trend $\left(-0.22\right.$ decade $\left.^{-1}\right)$ and significant reductions also in spring and annual values ( -0.14 and -0.17 decade $^{-1}$, respectively), suggesting an increase of evapotranspiration rates driven by higher temperature since precipitation do not show relevant variations.

The trend assessment performed on SPI and SPEI values computed at grid cell level allow to show the spatial variability of the indices. Areas exhibiting significant seasonal trends were found out in summer for SPI and in summer and spring for SPEI (Fig. 2a, 2c and 2d). More specifically, trends are negative and significant over the whole domain for SPEI while SPI gridded series experience significant negative trends over half domain and with lower TS slopes. Both indices report the most drying tendency in the south and the western parts of domain where SPEI trends reach -0.25 decade $^{-1}$. As shown in Fig. $2 b$ and 2e, annual SPI and SPEI trends are negative over the whole region with significant values in the western and south-western domain, respectively, where the decrease turned out to be lower than -0.15 decade $^{-1}$ for both indices. This area is located in the very central part of Po plain where the flat terrain is surrounded by the Prealps in the North, the close Apennines in the South and the Mediterranean influence is lower so that higher temperature, and therefore higher PET, could be enhanced. 


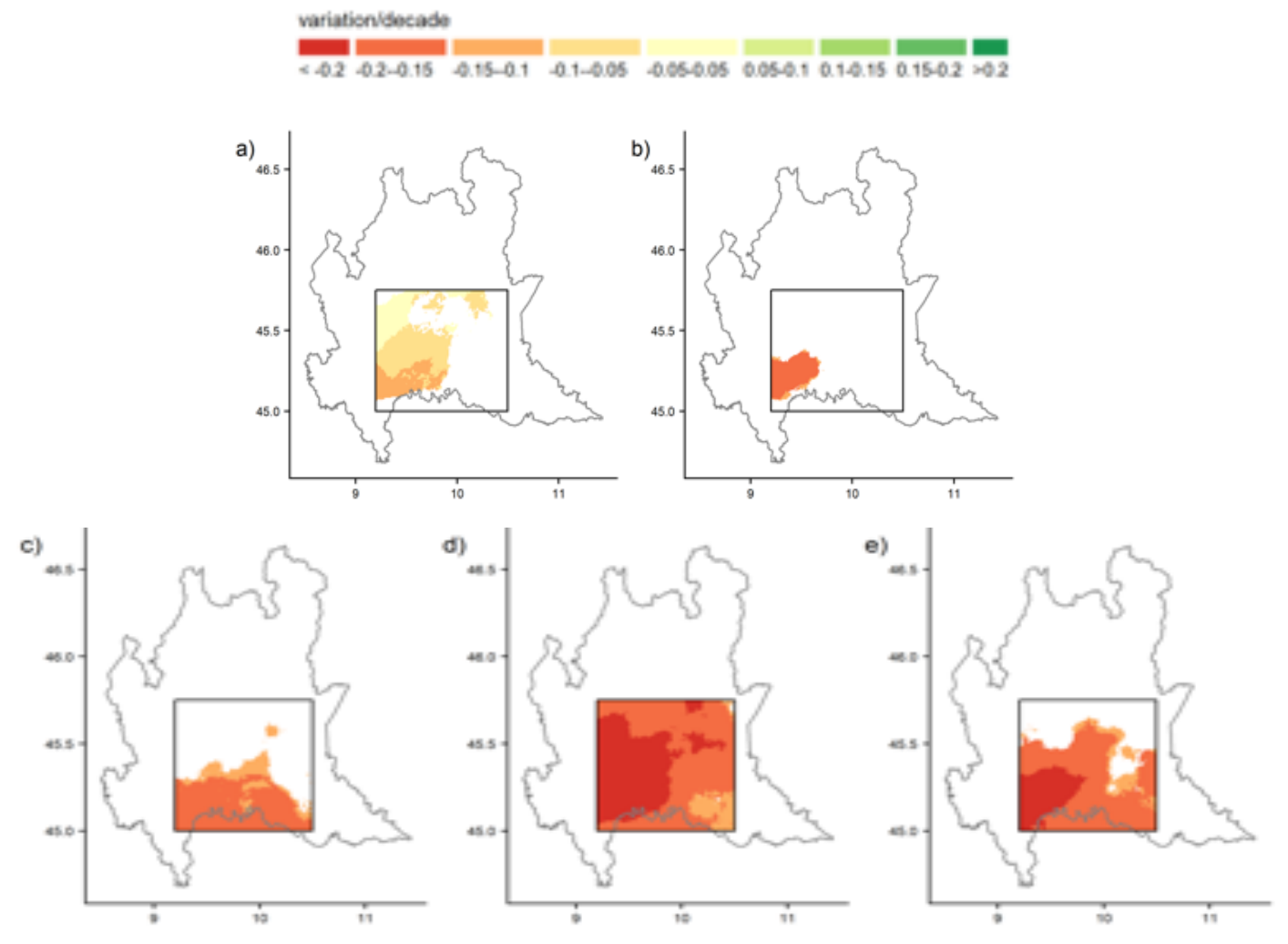

Fig. 2: distribution of SPI ( $a$ and b) and SPEI (c, d, e) significant trends in a) summer and b) year for SPI and in c) spring, d) summer and e) year for SPEI. The other seasons are not shown since no significant trend was depicted.

Besides SPI and SPEI series trends, specific drought features and their variability over subsequent decades were evaluated for each grid cell. In particular, the frequency of events (DF), the total severity (TSD) and total duration (TDD) were computed from monthly SPI and SPEI series for 1951 - 1960, 1961 - 1970, 1971 - 1980, 1981 1990, $1991-2000$ and 2001 - 2010. Drought starts in the month experiencing index values below -1 and ends when it returns positive for at least two consecutive months (McKee et al., 1993). Drought duration corresponds to the number of months between the start and the end (not included) of each episode, while severity is the absolute value of the integral area under the index curve. DF, TSD and TDD are the sum of number, intensity and duration of drought events occurred over the considered period, respectively (Spinoni et al., 2014).

For each grid cell, the spatio-temporal variability of the series of 6 decadal values for each drought feature was evaluated by applying a linear trend analysis and significance was computed by Student t-test with confidence level of $95 \%$. For both indices, trends are positive for south-western and south-eastern areas and lower, or even slight- 
ly negative for SPI indicators, in the central part of the domain. In particular, DF increases in the south-western part, while TDS and TDD show positive tendencies, especially for indicators extracted from SPEI, also in the south-eastern portion. Trends for SPI-3 indicators are not significant, except for very limited areas, while significance for all the indicators derived from SPEI is more evident and concerns the western and eastern areas, where TDD increases at a rate of more than 10 months per decade (Fig. 4 and Fig. 5).

Since trend analyses are based on 6 points only, the outcomes are to be considered as first indications of current tendencies and hot-spot area locations. Further ongoing analyses are addressed to improve the spatio-temporal characterization of drought over the domain and to identify the main local features influencing the positive trends observed.
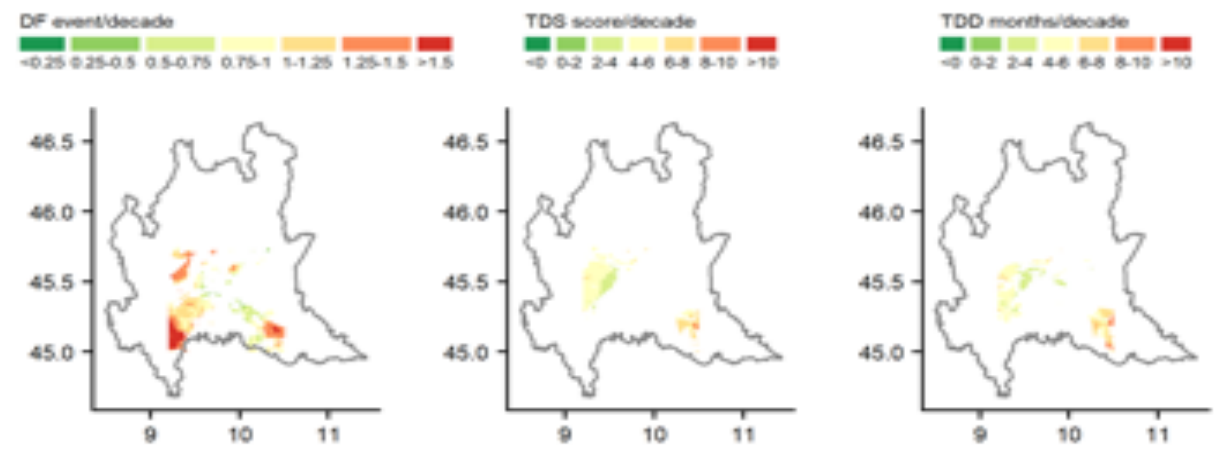

Fig. 4: Distribution of significant trends in decadal drought indicators (drought frequency DF, total
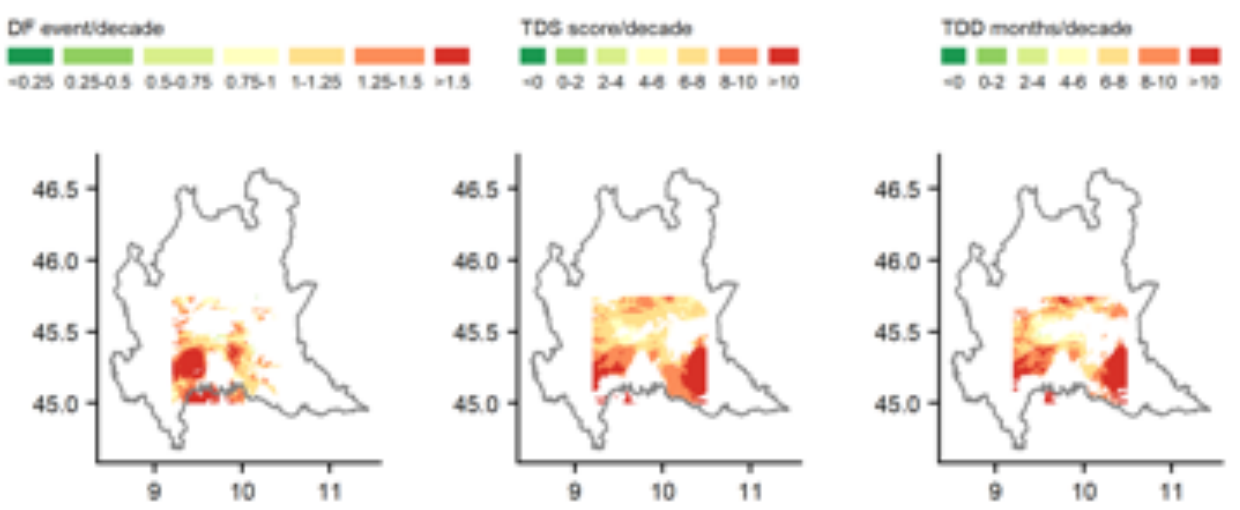

drought severity TDS and total drought duration TDD) extracted from the monthly SPI series.

Fig. 5: distribution of significant trends in decadal drought indicators (drought frequency DF, total drought severity TDS and total drought duration TDD) extracted from the monthly SPEI series. 


\section{Conclusions}

The spatio-temporal variability of the hydrological regime over a 67-year period in a portion of Po Plain (Northern Italy) was investigated by considering the meteorological drought indices SPI and SPEI. For this aim, the 1951-2017 gridded datasets of mean monthly temperature and total precipitation were computed at 30-arc second resolution by means of an anomaly-based interpolation approach. PET was defined from Thornthwaite equation and gridded deficit was also computed by subtracting PET field from total monthly precipitation values. SPI and SPEI were extracted over cumulated periods of 3 and 12 months at both cell level and regional scale, considering the average deficit and precipitation series of grid points, and seasonal and annual trends were evaluated. Significant drying tendencies were found out in summer for SPI (-0.14 decade $\left.{ }^{-1}\right)$ and in spring, summer and year for SPEI $(-0.14,-0.22$ and -0.17 decade $^{-1}$, respectively). The more relevant SPEI signal suggests a greater role of evapotranspiration driven by higher temperatures. The trend analysis at grid cell indicated that the area mostly experiencing drying tendencies are located in the south-western part, especially for annual indices.

Drought indicators in terms of frequency, total severity and total duration were computed over subsequent 10-year intervals spanning the whole study period and trend analysis was performed. Except for very limited areas, no significance is depicted for SPI-based indicators. More relevant tendencies are highlighted for indicators computed from SPEI and hot spots are located in the south-western and south-eastern parts of the study domain.

The results allowed to assess the spatial variability of drought at local level over the area and to highlight possible changes in future water availability. Further analyses are ongoing to better investigate the observed tendencies in drought indices and to identify the main drivers for the different zones; an extension of the study area is also foreseen in order to get a more comprehensive description of the hydrological cycle variability over Po Plain.

Acknowledgements The activity presented in the paper is part of the research grant "SO-WATCH - SOft path WATer management adaptation to CHanging climate", funded by Fondazione CARIPLO (www.fondazionecariplo.it).

\section{References}

Brunetti, M., Lentini, G., Maugeri, M., Nanni, T., Auer, I., Böhm, R. and Schöner, W. (2009). Climate variability and change in the Greater Alpine Region over the last two centuries based on multi-variable analysis. International Journal of Climatology 29, 2197-2225. doi: $10.1002 /$ joc. 1857 
Buttafuoco, G., Caloiero, T., and Coscarelli, R. (2015). Analyses of Drought Events in Calabria (Southern Italy) Using Standardized Precipitation Index. Water Resources Management 29, 557- 573. doi:10.1007/s11269-014-0842-5

Craddock, J. (1979). Methods of comparing annual rainfall records for climatic purposes, Weather 34, 332-346. doi:10.1002/j.1477-8696.1979.tb03465.x

Crespi, A., Brunetti, M., Maugeri, M., Ranzi, R., and Tomirotti, M. (2018a). 1845-2016 gridded dataset of monthly precipitation over the upper Adda river basin: a comparison with runoff series. Advances in Science and Research 15, 173-181. doi:10.5194/asr-15-173-2018

Crespi, A., Brunetti, M., Lentini, G., and Maugeri, M. (2018b). 1961-1990 high-resolution monthly precipitation climatologies for Italy. International Journal of Climatology 38, 878895. doi:10.1002/joc.5217

Daly, C., Gibson, W. P., Taylor, G. H., Johnson, G. L., and Pasteris, P. (2002). A knowledgebased approach to the statistical mapping of climate. Climate Research 22, 99-113. doi: $10.3354 / \mathrm{cr} 022099$

IPCC (2014). In Climate Change 2014: Synthesis Report. Contribution of Working Group II to the Fifth Assessment Report of the Intergovernmental Panel on Climate Change, Core Writing Team, Pachauri, R. K., Meyer, L. A. (eds). IPCC: Geneva, Switzerland, 151 pp.

IPCC (2018). Global Warming of $1.5^{\circ} \mathrm{C}$. Masson-Delmotte, V., P. Zhai, H.-O. Pörtner, D. Roberts, J. Skea, P.R. Shukla, A. Pirani, W. Moufouma-Okia, C. Péan, R. Pidcock, S. Connors, J.B.R. Matthews, Y. Chen, X. Zhou, M.I. Gomis, E. Lonnoy, Maycock, M. Tignor, and T. Waterfield (eds.) World Meteorological Organization, Geneva, Switzerland.

Isotta, F.A., Frei, C., Weilguni, V., Perčec Tadić, M., Lassègues, P., Rudolf, B., Pavan, V., Cacciamani, C., Antolini, G., Ratto, S.M., Munari, M., Micheletti, S., Bonati, V., Lussana, C., Ronchi, C., Panettieri, E., Marigo, G. and Vertačnik, G. (2014). The climate of daily precipitation in the Alps: development and analysis of a high-resolution grid dataset from panAlpine rain-gauge data. International Journal of Climatology 34, 1657-1675. doi:10.1002/ joc. 3794

McKee, T. B., Doesken, N. J., and Kleist, J. (1993). The relationship of drought frequency and duration to time scales. In Proceedings of the 8th Conference on Applied Climatology, Vol. 17. American Meteorological Society: Boston, MA, 179-183.

New, M., Hulme, M., and Jones, P. (2000). Representing Twentieth-Century Space-Time Climate Variability. Part II: Development of 1901-96 Monthly Grids of Terrestrial Surface Climate. Journal of Climate 13, 2217-2238. doi:10.1175/1520-0442(2000)013<2217:RTC$\mathrm{STC}>2.0 . \mathrm{CO} ; 2$

Piccarreta, M., Capolongo, D. and Boenzi, F. (2004), Trend analysis of precipitation and drought in Basilicata from 1923 to 2000 within a southern Italy context. International Journal of Climatology 24, 907-922. doi:10.1002/joc.1038

Scapin, S., Apadula, F., Brunetti, M., and Maugeri, M. (2015). The sensitivity of present-time electricity demand on past climate change: a case study for Italy. Earth Perspectives 4, 2194-6434. doi:10.1186/s40322-015-0030-7

Spinoni, J., Naumann, G., Carrao, H., Barbosa, P., and Vogt, J. (2014). World drought frequency, duration, and severity for 1951-2010. International Journal of Climatology 34, 2792-2804. doi: $10.1002 /$ joc. 3875 
Spinoni, J., Vogt, J. V., Naumann, G., Barbosa, P. and Dosio, A. (2018), Will drought events become more frequent and severe in Europe? International Journal of Climatology 38, 17181736. doi:10.1002/joc.5291

Stagge, J. H., Kingston, D. G., Tallaksen, L. M., Hannah, D. M. (2017). Observed drought indices show increasing divergence across Europe. Scientific Reports 7, 14045. doi:10.1038/ s41598-017-14283-2

Thornthwaite, C. W. (1948). An approach toward a rational classification of climate. Geographical Review, 38(1): 55-94. doi:10.2307/210739

Tsakiris G, Pangalou D, and Vangelis H. 2007. Regional drought assessment based on the reconnaissance drought index (RDI). Water Resources Management 21, 821-833. doi:10.1007/ s11269-006-9105-4

Vergni, L. and Todisco, F. (2011). Spatio-Temporal Variability of Precipitation, Temperature and Agricultural Drought Indices in Central Italy. Agricultural and Forest Meteorology 151, 301-313. doi:10.1016/j.agrformet.2010.11.005

Vicente-Serrano, S. M., Lopez-Moreno, J. I., Beguería, S., Lorenzo-Lacruz, J., Sanchez-Lorenzo, A., García-Ruiz, J. M., Azorin-Molina, C., Moran-Tejeda, E., Revuelto, J., Trigo, R., Coelho, F., and Espejo, F. (2014). Evidence of increasing drought severity caused by temperature rise in southern Europe. Environmental Research Letters 9, 044001. doi:10.1088/17489326/9/4/044001 